\title{
Holographic Sight Improves the Static Shooting Accuracy and Vertical Sway Precision During High-Intensity Dynamic Action in the Police Task Force
}

\author{
Michal Vágner, Zdeněk Bílek, Karel Sýkora, \\ Vladimír Michalička, Lubomír Přívětivý, and Miloš Fiala \\ Charles University \\ Adam Maszczyk \\ The Jerzy Kukuczka Academy of Physical Education
}

\author{
Petr Stastny \\ Charles University
}

\begin{abstract}
The aim of this study was to find the effect of holographic sight (HS) on shortdistance shooting accuracy and precision during static and high-intensity dynamic actions. Twenty policemen $(31 \pm 2.2$ years, $85.6 \pm 6.1 \mathrm{~kg}$, and $181.9 \pm 4.4 \mathrm{~cm})$ performed five shots in the 10-s limit under the static condition for $20 \mathrm{~m}$ and dynamic condition $15-5 \mathrm{~m}$, and after $4 \times 10 \mathrm{~m}$ sprint action, both with fixed sight (FS) and HS. The analysis of variance post hoc test revealed that $\mathrm{HS}_{\text {static }}$ had higher shouting accuracy than $\mathrm{FS}_{\text {static }}, \mathrm{FS}_{\text {dynamic }}$, and $\mathrm{HS}_{\text {dynamic }}(p=.03$, $p=.0001$, and $p=.0001$, respectively) and $\mathrm{FS}_{\mathrm{dynamic}}$ had lower precision than $\mathrm{FS}_{\text {static }}, \mathrm{HS}_{\text {static }}$, and $\mathrm{HS}_{\text {dynamic }}(p=.0003, p=.0001$, and $p=.01$, respectively) in vertical sway. The HS for rifles has improved the accuracy of static shooting and vertical sway precision of dynamic shooting.
\end{abstract}

Keywords: collimator, military, police, precision, tactical training

\footnotetext{
Vágner, Sýkora, Michalička, and Př́ivětivý are with the Department of Military Physical Education, Faculty of Physical Education and Sport, Charles University, Prague, Czech Republic. Vágner and Stastny are with the Department of Sports Games, Faculty of Physical Education and Sport, Charles University, Prague, Czech Republic. Bílek and Fiala are with the Faculty of Physical Education and Sport, Charles University in Prague, Prague, Czech Republic. Sýkora is also with the Department of Adapted Physical Education and Sport Medicine, Faculty of Physical Education and Sport, Charles University, Prague, Czech Republic. Michalička is also with the Department of Physiotherapy, Faculty of Physical Education and Sport, Charles University, Prague, Czech Republic. Maszczyk is with the Department of Sports Theory, The Jerzy Kukuczka Academy of Physical Education, Katowice, Poland. Vágner (vagner@ftvs.cuni.cz) is corresponding author.
} 
Rifle shooting is a fine motor control task that requires the combination of visual, vestibular, and self-motion perception. This combination became extremely important in activities of emergency tactical personnel such as patrol soldiers or police officers in their duties, where the typical action requires to shoot from a short distance to about $20 \mathrm{~m}$ while covered behind a barrier or cautiously approaching the target (Robles-Pérez, Aguirre-Puig, Montañez-González, Jesús Ramos-Campos, \& Clemente-Suárez, 2014). Both, static and dynamic actions have to be fast and performed with multiple shots to eliminate opponent counterstrike, where multiple shots are realistically applicable only with high shooting accuracy and precision (Brown \& Mitchell, 2017). In this psychologically demanding situation, it is not easy to maintain appropriate shooting performance (Chung, Delacruz, de Vries, Bewley, \& Baker, 2006; Kelley et al., 2011), because visual cues entail the danger of self-motion illusions (Mergner, Schweigart, Müller, Hlavacka, \& Becker, 2000). In that case, selfmotion perception is related to the visual scene as a reference, while the vestibular check the kinematic part of the action (visual-somatosensory and vestibular-somatosensory conflicts; Maurer, Mergner, Bolha, \& Hlavacka, 2000).

Several studies of biathlon and military personnel determined the general factors influencing rifle shooting performance in short distance $10 \mathrm{~m}$ (static target and moving target), which identified stability of hold, aiming time, cleanness of triggering, aiming accuracy, and timing of triggering as the main principal factors (Ihalainen, Kuitunen, Mononen, \& Linnamo, 2016; Mononen, Viitasalo, Era, \& Konttinen, 2003; Zatsiorsky \& Aktov, 1990). Along with those factors, the patrol tactical personnel are moving during the action under high time pressure and physiological stress, which can deepen the impact of the previously mentioned factors and possibly bring other ones into account (Chung et al., 2006; Robles-Pérez et al., 2014). In this consequence, visual-somatosensory and vestibular-somatosensory conflicts can disrupt body stability, where vision is the major contributor while walking and standing (Hirjaková, Bizovská, Bzdúšková, Hlavačka, \& Janura, 2020). However, there is a principal question, how to train or improve the shooting accuracy for practical use on short distances up to $20 \mathrm{~m}$ and in connection with the ongoing high-intensity dynamic actions.

It has been documented that physiological exhaustion has minimal influence on prone shooting performance (Brown, Tandy, Wulf, \& Young, 2013) but does affect shooting in the standing position by altering the stability of the hold, which influences the vertical rifle sway (Hoffman, Gilson, Westenburg, \& Spencer, 1992; Sattlecker, Buchecker, Gressenbauer, Müller, \& Lindinger, 2017). Another example is that the 30-min loaded march decreased the precision and accuracy of shooting with rifle M4 in military personnel, however not the overall shooting performance (Lee, Tan, \& Tan, 2017). The possible improvement of the accuracy lies in the reduction of horizontal sway and anteriorposterior fluctuations (the equivalent of vertical sway; Balasubramaniam, Riley, \& Turvey, 2000), which can explain up to $26 \%$ of the shooting score variance (Mononen, Konttinen, Viitasalo, \& Era, 2007), and where visual control has an exclusive role for maintaining a stable posture (Goonetilleke, Hoffmann, \& Lau, 2009; Hirjaková et al., 2020). This is supported by the knowledge that novice 
shooters were more reliant on visual-spatial processing (Konttinen, Lyytinen, \& Viitasalo, 2007), which could lead to the suggestion that optoelectronic devices such as holographic sights (HS) can improve aiming to the target. However, the effect of HS on horizontal sway, vertical sway, and shooting accuracy remain scarce in current literature.

Since the HS has the potential to improve short shooting performance and reduce the vertical sway, while its effect under static and dynamic conditions is unknown, this study aimed to find the effect of HS on short-distance shooting accuracy and precision in the horizontal and vertical plane during static and highintensity dynamic actions. Based on the previous studies, we hypothesize that static and dynamic rifle shooting with the HS will be more accurate and precise than rifle shooting with fixed sight (FS) in all conditions.

\section{Methods}

\section{Procedure}

The cross-sectional measurement in outdoor shooting range (Brehyne, Czech Republic, air temperature $24^{\circ} \mathrm{C}$, relative humidity $72 \%$, and air pressure 805 Torrs, clear weather) was performed at different conditions in the following order: static shooting with $\mathrm{HS}\left(\mathrm{HS}_{\text {static }}\right)$, static shooting with FS $\left(\mathrm{FS}_{\text {static }}\right)$, dynamic shooting with $\mathrm{HS}\left(\mathrm{HS}_{\mathrm{dynamic}}\right)$, and dynamic shooting with FS ( $\left.\mathrm{FS}_{\text {dynamic }}\right)$ (Figure 1). Individual shooting tests included five shots in 10-s time limits, with static conditions, and were performed at $20 \mathrm{~m}$. The dynamic conditions were performed while walking from 15 to $5 \mathrm{~m}$ approaching the target immediately after the maximum effort shuttle run for $4 \times 10 \mathrm{~m}$ (Figure 1). The start and finish of each task were signaled by a whistle. The specified firing distance from 5 to $20 \mathrm{~m}$ was determined based on typical requirements for dealing with situations requiring rapid-fire in close-quarter combat and emergency tactical personnel (Guillaume, 2010; Robles-Pérez et al., 2014). The number of evaluated shots was chosen based on the recommendation of five shots to identify the accuracy and precision of shooting (Angel, Christian, \& Massel, 2005).

The study protocol was approved by the institutional review board of the Faculty of Physical Education and Sport, Charles University in Prague (No. 097/ 2017), and written informed consent was obtained from the unpaid volunteers before enrollment in the study. All procedures were performed following the Declaration of Helsinki 2013.

\section{Subjects}

Twenty males from the riot police $(31 \pm 2.2$ years, $85.6 \pm 6.1 \mathrm{~kg}, 181.9 \pm 4.4 \mathrm{~cm}$, and $5.9 \pm 1.5$ years of experience in shooting) experienced in shooting volunteered for the study. All subjects were healthy and free of injury or any health problems for 3 months before the study. Exclusion criteria were traumatic injury affecting performance or musculoskeletal injury within 3 months before the start of the study. The participants attended two familiarization sessions to gain experience with the protocol prior to testing and were instructed not to perform any physically demanding activity 3 days before the testing day. 


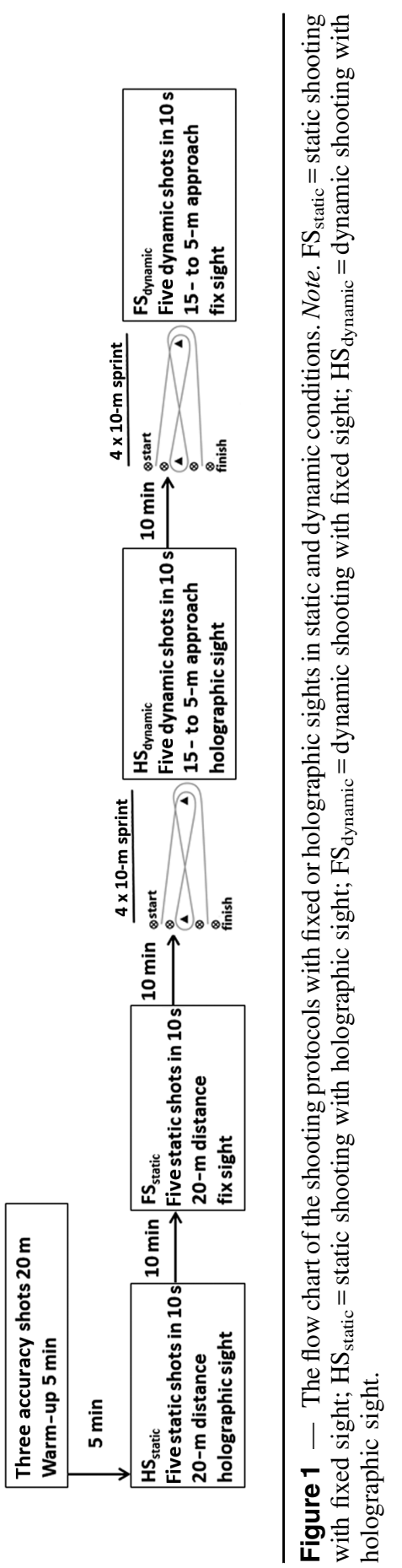




\section{Equipment}

The HK MP5 (Heckler \& Koch, Oberndorf am Neckar, Germany) $9 \times 19-\mathrm{mm}$ Parabellum submachine gun was chosen as the weapon used for the study itself. In the case of using a collimator, it was a HS EOTECH 512 (EOTech, Ann Arbor, MI). The ammunition used was $9 \times 19-\mathrm{mm}$ full metal jacket, weighing $115 \mathrm{~g}$, Sellier \& Bellot (Sellier \& Bellot, Vlašim, Czech Republic). International pistol targets 50/20 were also used for the study. The participants were dressed in standard police uniform model 92.

\section{Shooting Accuracy and Precision}

All impact point values in the target were analyzed to calculate precision and the accuracy of shooting according to the methodology of the Marine Corps Systems for Small Arms applications (Gammon, 2017). The evaluation of the dispersion of the impact points was determined with respect to the center of the target and the system of rectangular coordinates, which allows determining the $x$ and $y$ impact point positions. The accuracy of shooting was defined as the direct distance from the target center. The precision of shooting was defined as the dispersion in the $x$ and $y$-axis. For each individual, the average from five impact points was calculated for each shooting exercise $\left(\mathrm{HS}_{\text {static }}, \mathrm{FS}_{\text {static }}, \mathrm{HS}_{\text {dynamic }}\right.$, and $\left.\mathrm{FS}_{\text {dynamic }}\right)$, numerically in centimeters.

\section{Statistical Analysis}

All statistical analyses were performed using Statistica (TIBCO Statistika, version 13.5; TIBCO Software Inc, Palo Alto, CA) and Microsoft Excel (Microsoft Corporation, Redmond, WA) using an alpha level of .05. Shapiro-Wilk test for data normality was calculated. The accuracy and precision of shooting comparison were performed using a one-way analysis of variance using Tukey's post hoc test for differences between $\mathrm{HS}_{\text {static }}, \mathrm{FS}_{\text {static }}, \mathrm{HS}_{\text {dynamic }}$, and $\mathrm{FS}_{\text {dynamic }}$ and effect size by partial eta square $\left(\mu^{2}\right)$ and Cohen's delta $(d)$. The Cohen's $d 0.2,0.5$, and 0.8 corresponded to small, medium, and large effects (Hopkins, Marshall, Batterham, \& Hanin, 2009).

\section{Results}

All participants completed all testing conditions within the defined time limit and had five shots on the target. The data normality was not disrupted according to the Shapiro-Wilk test (Table 1).

There were differences in accuracy of shooting between shooting conditions, $F(3,76)=17.77, p<.0001, \mu^{2}=0.41$; Figure 2 , where post hoc testing revealed that $\mathrm{HS}_{\text {static }}$ was more accurate than $\mathrm{FS}_{\text {static }}, \mathrm{FS}_{\text {dynamic }}$, and $\mathrm{HS}_{\text {dynamic }}(p=.03, d=$ $0.929 ; p=.0001, d=2.379$; and $p=.0001, d=1.994$, respectively), and $\mathrm{FS}_{\text {static }}$ was more accurate than $\mathrm{HS}_{\text {dynamic }}$ and $\mathrm{FS}_{\text {dynamic }}(p=.003, d=0.859$ and $p=.016$, $d=1.069$, respectively). The difference between $\mathrm{FS}_{\text {static }}$ and $\mathrm{HS}_{\text {static }}$ was $1.82 \mathrm{~cm}$, and there was a significant difference $(p=.03, d=0.929)$. The difference between $\mathrm{FS}_{\mathrm{dynamic}}$ and $\mathrm{HS}_{\text {dynamic }}$ was $0.35 \mathrm{~cm}$, and there was no significant difference $(p=.950, d=0.159)$. 
Table 1 The Accuracy and Precision of Shooting in Different Visual and Postural Conditions

\begin{tabular}{|c|c|c|c|c|c|c|c|c|c|}
\hline \multirow{3}{*}{$\begin{array}{l}\text { Shooting } \\
\text { conditions } \\
\text { (cm) }\end{array}$} & \multicolumn{3}{|c|}{ Accuracy } & \multicolumn{3}{|c|}{$\begin{array}{l}\text { Precision of shooting } \\
\text { (horizontal sway) }\end{array}$} & \multicolumn{3}{|c|}{$\begin{array}{l}\text { Precision of shooting } \\
\text { (vertical sway) }\end{array}$} \\
\hline & \multicolumn{3}{|c|}{$95 \%$} & \multicolumn{3}{|c|}{$95 \%$} & \multicolumn{3}{|c|}{$95 \%$} \\
\hline & Mean $\pm S D$ & $\mathrm{Cl}$ & sw & Mean $\pm S D$ & $\mathrm{Cl}$ & sw & Mean $\pm S D$ & $\mathrm{Cl}$ & sw \\
\hline $\mathrm{HS}_{\text {static }}$ & $4.85 \pm 1.48$ & $\begin{array}{r}{[4.16,} \\
5.54]\end{array}$ & 0.979 & $2.56 \pm 1.45$ & $\begin{array}{l}{[1.88,} \\
3.24]\end{array}$ & 0.890 & $2.93 \pm 1.76$ & $\begin{array}{l}{[2.11} \\
3.75]\end{array}$ & 0.963 \\
\hline $\mathrm{FS}_{\text {static }}$ & $6.68 \pm 2.36$ & $\begin{array}{l}{[5.58,} \\
7.78]\end{array}$ & 0.964 & $3.29 \pm 1.60$ & $\begin{array}{l}{[2.55,} \\
4.04]\end{array}$ & 0.943 & $3.60 \pm 1.42$ & $\begin{array}{l}{[2.93} \\
4.27]\end{array}$ & 0.936 \\
\hline $\mathrm{HS}_{\text {dynamic }}$ & $9.01 \pm 1.98$ & $\begin{array}{l}{[8.09,} \\
9.94]\end{array}$ & 0.943 & $4.65 \pm 2.52$ & $\begin{array}{r}{[3.47} \\
6.82]\end{array}$ & 0.937 & $4.38 \pm 2.26$ & $\begin{array}{l}{[3.32} \\
5.43]\end{array}$ & 0.991 \\
\hline $\mathrm{FS}_{\text {dynamic }}$ & $8.67 \pm 2.27$ & $\begin{array}{l}{[7.60} \\
9.73]\end{array}$ & 0.981 & $3.96 \pm 1.95$ & $\begin{array}{l}{[3.04,} \\
4.87]\end{array}$ & 0.965 & $6.42 \pm 2.45$ & $\begin{array}{l}{[5.28,} \\
7.57]\end{array}$ & 0.959 \\
\hline
\end{tabular}

Note. $\mathrm{CI}=$ confidence interval [upper, lower limit]; $\mathrm{SW}=$ Shapiro-Wilk test; $\mathrm{HS}_{\text {static }}=$ holographic sight in static condition; $\mathrm{FS}_{\text {static }}=$ fixed sight in static condition; $\mathrm{HS}_{\mathrm{dynamic}}=$ holographic sight in dynamic condition; $\mathrm{FS}_{\mathrm{dy}-}$ namic $=$ fixed sight in dynamic condition.

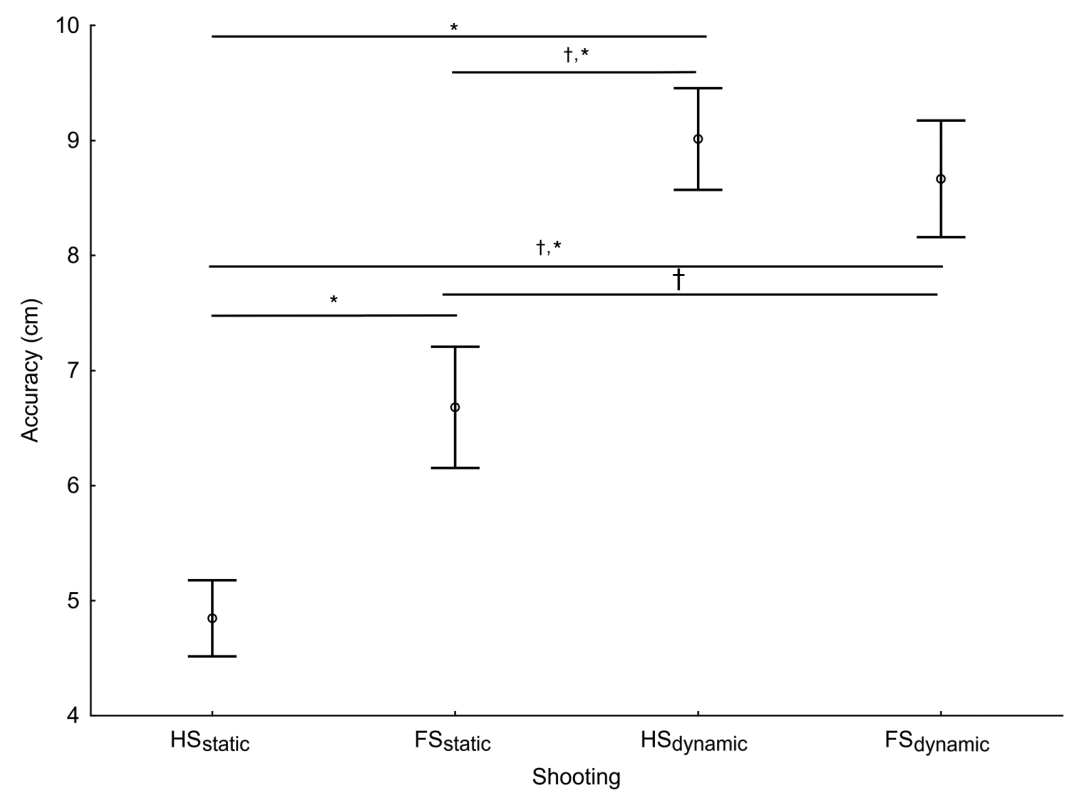

Figure 2 - Accuracy of shooting in different visual and postural conditions. Note. $\mathrm{FS}_{\text {static }}=$ static shooting with fixed sight; $\mathrm{HS}_{\text {static }}=$ static shooting with holographic sight; $\mathrm{FS}_{\text {dynamic }}=$ dynamic shooting with fixed sight; $\mathrm{HS}_{\text {dynamic }}=$ dynamic shooting with holographic sight. *Significant difference between HS and FS. ${ }^{\dagger}$ Significant difference between static shooting and dynamic shooting, $p \geq .05$. 
There were differences of shooting precision on the $x$-axis $F(3,76)=4.31$, $p<.007, \mu^{2}=0.15$; Figure 3 , where post hoc testing revealed that $\mathrm{FS}_{\text {static }}$ was more precise than $\mathrm{HS}_{\text {dynamic }}(p=.005, d=0.644)$, and there was not any difference between other static and dynamic shooting (Figure 3). The difference between $\mathrm{FS}_{\text {static }}$ and $\mathrm{HS}_{\text {static }}$ was $0.73 \mathrm{~cm}$, and there was no significant difference $(p=.625$, $d=0.478$ ). The difference between $\mathrm{FS}_{\mathrm{dynamic}}$ and $\mathrm{HS}_{\mathrm{dynamic}}$ was $0.69 \mathrm{~cm}$, and there was no significant difference $(p=.671, d=0.306)$.

There were differences of shooting precision on the $y$-axis $F(3,76)=11.294$, $p<.0001, \mu^{2}=0.31$; Figure 3 , where post hoc testing revealed that $\mathrm{FS}_{\text {dynamic }}$ was less precise than $\mathrm{FS}_{\text {static }}, \mathrm{HS}_{\text {static }}$, and $\mathrm{HS}_{\text {dynamic }}(p=.0003, d=1.408 ; p=.0001$, $d=1.636$; and $p=.01, d=0.886$, respectively; Figure 3 ). The difference between $\mathrm{FS}_{\text {static }}$ and $\mathrm{HS}_{\text {static }}$ was $0.67 \mathrm{~cm}$, and there was no significant difference $(p=.722$, $d=0.419)$. The difference between $\mathrm{FS}_{\mathrm{dynamic}}$ and $\mathrm{HS}_{\mathrm{dynamic}}$ was $2.12 \mathrm{~cm}$, and there was a significant difference $(p=.01, d=0.886)$.

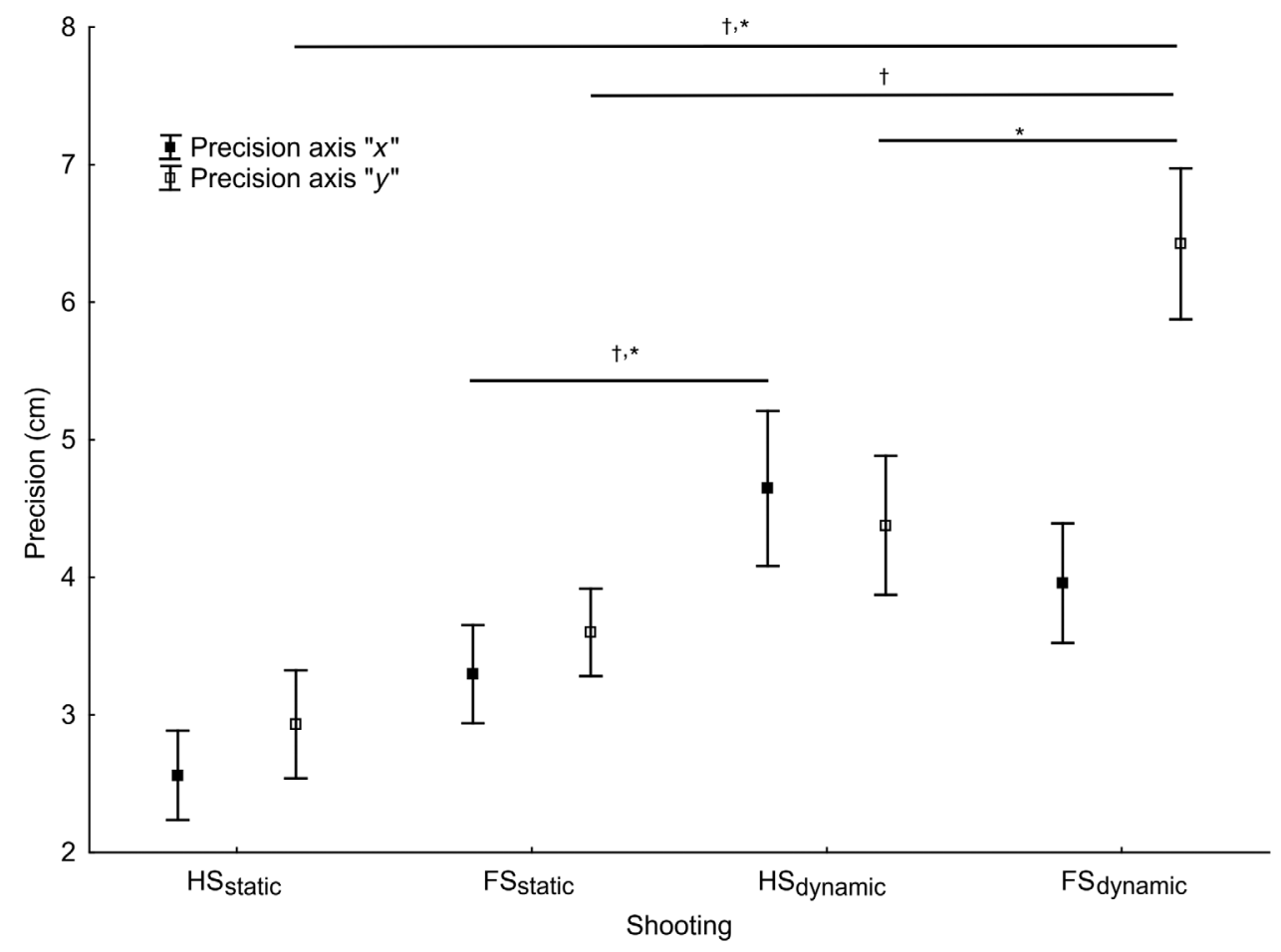

Figure 3 - The precision of shooting in different visual and postural conditions. *Significant difference between HS and FS. 'Significant difference between static shooting and dynamic shooting, $p \geq .05$. Note. $\mathrm{FS}_{\text {static }}=$ static shooting with fixed sight; $\mathrm{HS}_{\text {static }}=$ static shooting with holographic sight; $\mathrm{FS}_{\text {dynamic }}=$ dynamic shooting with fixed sight; $\mathrm{HS}_{\mathrm{dynamic}}=$ dynamic shooting with holographic sight. 


\section{Discussion}

The main differences were found between FS and HS in the precision of dynamic shooting in a vertical sway (axis $y$ ) and in the accuracy of shooting in the static shooting, which did confirm our hypothesis only in those conditions. In static shooting, the use of HS was better than FS in the accuracy, but not in the dynamic shooting accuracy and horizontal sway precision. However, we can identify the use of HS as beneficial of shooting performance, especially in the phenomenon of vertical sway (Balasubramaniam et al., 2000; Hirjaková et al., 2020; Hoffman et al., 1992; Mononen et al., 2007; Sattlecker et al., 2017). Since the HS improves the accuracy and vertical sway during the shouting, we can support the premise that vision is one of the major factor contributing to dynamic posture stabilization (Hirjaková et al., 2020) and that visual conditions influence the postural sway strategy (Dozza, Chiari, Hlavacka, Cappello, \& Horak, 2006). The mechanism of HS effects might be similar as during the visual body feedback, where the reduction of vertical (anterior-posterior) body sway is highest in the body segment from which the visual body feedback is sensed (Halická, Lobotková, Bučková, \& Hlavačka, 2014). This might be because the HS refers to the positions of the upper limbs holding the rifle.

An important aspect of our study was the fast action task performed as dynamic action before the dynamic shooting under time pressure. This imitates the real action such as short run from a car or runs upstairs before the use of selfdefense or the use of a weapon in a very short time, where most of the combat durations happen in less than $20 \mathrm{~s}$; specifically $31 \%$ in $5 \mathrm{~s}$, and $54 \%$ between 5 and $20 \mathrm{~s}$ (Robles-Pérez et al., 2014). The time pressure interacts with the fatigue of shooters (Sattlecker et al., 2017), where the dynamic precision improvement of $2.12 \mathrm{~cm}$ by HSs is considered as an essential difference. On the other hand, the lack in the improvement of dynamic shooting accuracy by HSs does not matter, since fast action does not premise that the first shot would be the decisive hit to the target, but repeated shots to the selected area should eliminate the opponents. Therefore, the HSs help to eliminate shooting disrupting factors of time and physical stress.

From a practical point of view, the execution of static shooting is important not only for routine training but also for the protection of persons or close-quarter combat in small units. In this case, on the contrary, it is necessary to eliminate the attacker with the first hit for the protection of other persons, and therefore, it is necessary to aim accurately. Aiming accuracy, aiming time, and stability of hold were identified as common shooting technical components in all of the shooting events (air rifle, running target, and pistol shooting; Ihalainen et al., 2016). In static shooting, the stability of hold is not too disturbed, and the aiming time is longer for aiming accuracy. The accuracy of the shot in static shooting can be affected by the sights, as the shooter is not sure of the aiming accuracy when using a FS. This problem can largely be eliminated by using a HS. This was also shown in our research, where subjects achieved the best results in static shooting with a HS.

Shooting in dynamic action is crucial in many police pursuits when the attackers also defend themselves with a firearm. Therefore, fast action in dynamic shooting is very important both for the elimination of the attacker and for the safety of other participants in the action. Goonetilleke et al. (2009) have proved that 
limited viewing time plays a role only $\leq 3 \mathrm{~s}$ for novice shooters and $\leq 2 \mathrm{~s}$ for experienced shooters, respectively. If the time would be longer, the shooting would not be relevant for the real emergency tasks. Moreover, when walking, the center of gravity of the shooter decreases and increases, which is transmitted to the weapon, and thus worsens the precision aiming at the target. This was also probably one of the reasons why the shooters achieved the worst precision in vertical sway in dynamic shooting with FS in our study. On the contrary, the use of HS in dynamic shooting has significantly improved the precision of vertical sway of shooting. However, this effect did not manifest in horizontal sway in our study. This fact is consistent with the study of Mononen et al. (2007), who stated that horizontal and vertical sway are independent variables in the accuracy of shooting. In this context, Balasubramaniam et al. (2000) stated that when the precision task requires minimizing fluctuations in the medial-lateral direction (horizontal sway), fluctuations in the anterior-posterior (vertical sway) direction became correspondingly magnified with task difficulty. In context with shooting, Brown and Mitchell (2017) stated that the axis $x$ (horizontal sway), and trigger control in the dynamic shooting with FS provides a good predictivity of precision. This may be the reason why HS had not improved the accuracy and precision of horizontal sway in dynamic shooting in our study (Figures 2 and 3 ).

Another variable that can affect shooting strategies is the need for visualspatial control, which can vary according to the level of the shooter. In this context, Konttinen et al. (2007) stated in their study that elite athletes applied different riflehold strategies. The elite shooters concentrated primarily on achieving a stable rifle position using psychomotor regulation, whereas the preelite shooters were more reliant on visual-spatial processing. The need for visual-spatial processing can also be affected by time pressure and walking when shooting. Therefore, if a preelite shooter must concentrate visually on the control of the rifle and at the same time on the surroundings, then his accuracy and precision of shooting may decrease but might be compensated by HS. Moreover, effective shooting under time pressure is also very demanding to control breathing (as we previously mentioned ), body position, and the trigger finger. It is also clear if the shooter's sight alignment is off by a fraction of an inch, the shooter is unlikely to hit the target (Chung et al., 2006). However, if shooters can use HSs, they may be able to mitigate these negative factors and achieve better accuracy in static shooting and precision of vertical sway in a dynamic shooting.

This study is limited by the specificity of a fast action task, which is typically designed for police action imitation, and the average time limits $2 \mathrm{~s}$ per shot, which might be even shorter compared with a real-life event. In particular, the design of the study was constructed without measurement of dynamic shooting before the dynamic action $(4 \times 10 \mathrm{~m})$ but only after dynamic action, where future studies should design the comparison of HSs effect after speed, power, and strength conditions (e.g., to $30 \mathrm{~s}$ upstairs run or breaking barriers). Another limit is the absence of the dynamic stability measures related to postural sway. Postural balance and rifle stability (Mononen et al., 2007) make a difference between the performance levels of shooters (Aalto, Pyykkö, Ilmarinen, Kähkönen, \& Starck, 1990; Era, Konttinen, Mehto, Saarela, \& Lyytinen, 1996; Mon, Zakynthinaki, Cordente, Monroy Antón, \& López Jiménez, 2014), where the measure of dynamics stability would justify whether the HS improves systematic aiming 
error, vestibular, proprioceptive control, or their combination. Moreover, further research should also focus on how the use of HS to shorten targeting time and total measurement time, and what are the role of decision making and physiological stress (Chung et al., 2006; Robles-Pérez et al., 2014).

In conclusion, it is possible to summarize that HS has improved the accuracy of static shooting, vertical sway precision of dynamic shooting but slightly deteriorated accuracy, and precision in horizontal sway in the dynamic shooting. The visual control (interacting with vestibular control) can be probably improved by HS because the shooter can focus more on body support. The body support is related to a proprioceptive control mechanism and thus is possible that the shooter will achieve improvement in the vertical axis in the precision of the dynamic shooting during the forward motion. On the other hand, this assumption does not prove in the horizontal axis. However, this does not mean that precision in the horizontal axis should not be further trained when using a HS.

\section{Practical Applications}

Tactical personnel should use HSs for rifle dynamic shooting during static and high dynamic action, especially when shooting while walking forward to the target. However, the expectation of its utilization is primarily in the improvement of vertical sway in dynamic shooting and accuracy in a static position. Although some structural improvement of shooting performance in vertical sway is given by the HS, the shooting training with HSs should be also focused on controlling the horizontal axis during the forward motion.

\section{Acknowledgments}

This study was supported by Charles University grant UNCE/HUM/032. The authors claim no conflict of interest.

\section{References}

Aalto, H., Pyykkö, I., Ilmarinen, R., Kähkönen, E., \& Starck, J. (1990). Postural stability in shooters. ORL, 52(4), 232-238. PubMed ID: 2392286 doi:10.1159/000276141

Angel, H.A., Christian, A.B., \& Massel, L.J. (2005). Examination of the effect of off-bore shooting on rifle target engagement accuracy during simulated engagements (Report No. CR-2005-070, pp. 66). Toronto, Canada: Defense Research and Development Canada.

Balasubramaniam, R., Riley, M.A., \& Turvey, M.T. (2000). Specificity of postural sway to the demands of a precision task. Gait \& Posture, 11(1), 12-24. PubMed ID: 10664481 doi:10.1016/S0966-6362(99)00051-X

Brown, M.J., Tandy, R.D., Wulf, G., \& Young, J.C. (2013). The effect of acute exercise on pistol shooting performance of police officers. Motor Control, 17(3), 273-282. PubMed ID: 23756320

Brown, S.A.T., \& Mitchell, K.B. (2017). Shooting stability: A critical component of marksmanship performance as measured through aim path and trigger control. Proceedings of the Human Factors and Ergonomics Society Annual Meeting, 61(1), 1476-1480. doi:10.1177/1541931213601854 
Chung, G., Delacruz, G.C., de Vries, L.F., Bewley, W.L., \& Baker, E.L. (2006). New directions in rifle marksmanship research. Military Psychology, 18(2), 161-179. doi:10.1207/s15327876mp1802_5

Dozza, M., Chiari, L., Hlavacka, F., Cappello, A., \& Horak, F.B. (2006). Effects of linear versus sigmoid coding of visual or audio biofeedback for the control of upright stance. IEEE Transactions on Neural Systems and Rehabilitation Engineering, 14(4), 505-512. PubMed ID: 17190042 doi:10.1109/TNSRE.2006.886732

Era, P., Konttinen, N., Mehto, P., Saarela, P., \& Lyytinen, H. (1996). Postural stability and skilled performance-A study on top-level and naive rifle shooters. Journal of Biomechanics, 29(3), 301-306. PubMed ID: 8850636 doi:10.1016/0021-9290(95) 00066-6

Gammon, W.J. (2017). Shot group statistics for small arms applications (Report No. AD1034885, pp. 82). Quantico, VA: Marine Corps Systems Command. Retrieved from https://apps.dtic.mil/sti/citations/AD1034885

Goonetilleke, R.S., Hoffmann, E.R., \& Lau, W.C. (2009). Pistol shooting accuracy as dependent on experience, eyes being opened and available viewing time. Applied Ergonomics, 40(3), 500-508. PubMed ID: 18992872 doi:10.1016/j.apergo.2008. 09.005

Guillaume, Y.N. (2010). Close quarters combat shooting (Report No. 0704-0188, pp. 41). Quantico, VA: USMC Command and Staff College.

Halická, Z., Lobotková, J., Bučková, K., \& Hlavačka, F. (2014). Effectiveness of different visual biofeedback signals for human balance improvement. Gait \& Posture, 39(1), 410-414. PubMed ID: 24001870 doi:10.1016/j.gaitpost.2013.08.005

Hirjaková, Z., Bizovská, L., Bzdúšková, D., Hlavačka, F., \& Janura, M. (2020). Postural stability after treadmill and overground walking in young and elderly. Gait \& Posture, 80, 84-89. PubMed ID: 32497980 doi:10.1016/j.gaitpost.2020.05.014

Hoffman, M., Gilson, P., Westenburg, T., \& Spencer, W. (1992). Biathlon shooting performance after exercise of different intensities. International Journal of Sports Medicine, 13(03), 270-273. doi:10.1055/s-2007-1021265

Hopkins, A.G., Marshall, S.W., Batterham, A.M., \& Hanin, J. (2009). Progressive statistics for studies in sports medicine and exercise science. Medicine \& Science in Sports \& Exercise, 41(1), 3-12. PubMed ID: 19092709 doi:10.1249/MSS.0b013e31818cb278

Ihalainen, S., Kuitunen, S., Mononen, K., \& Linnamo, V. (2016). Determinants of elite-level air rifle shooting performance. Scandinavian Journal of Medicine \& Science in Sports, 26(3), 266-274. PubMed ID: 25850700 doi:10.1111/sms.12440

Kelley, A.M., Athy, J.R., King, M., Rickson, B.E., Chiaramonte, J., Vasbinder, M., \& Thompson, A. (2011). Think before you shoot: The relationship between cognition and marksmanship (Report No. 2011-23, pp. 33). Fort Rucker, AL: United States Army Aeromedical Research Laboratory.

Konttinen, N., Lyytinen, H., \& Viitasalo, J. (2007). Rifle-balancing in precision shooting: Behavioral aspects and psychophysiological implication. Scandinavian Journal of Medicine \& Science in Sports, 8(2), 78-83. doi:10.1111/j.1600-0838.1998.tb00172.x

Lee, T., Tan, M., \& Tan, P. (2017). Effects of loaded march on marksmanship performance. Journal of Science and Medicine in Sport, 20(Suppl. 2), S176. doi:10.1016/j.jsams. 2017.09.576

Maurer, C., Mergner, T., Bolha, B., \& Hlavacka, F. (2000). Vestibular, visual, and somatosensory contributions to human control of upright stance. Neuroscience Letters, 281(2-3), 99-102. PubMed ID: 10704752 doi:10.1016/S0304-3940(00)00814-4

Mergner, T., Schweigart, G., Müller, M., Hlavacka, F., \& Becker, W. (2000). Visual contributions to human self-motion perception during horizontal body rotation. Archives Italiennes de Biologie, 138(2), 139-166. PubMed ID: 10782255 doi:10. 4449/aib.v138i2.530 
Mon, D., Zakynthinaki, M.S., Cordente, C.A., Monroy Antón, A., \& López Jiménez, D. (2014). Validation of a dumbbell body sway test in Olympic air pistol shooting. PLoS One, 9(4), e96-106. doi:10.1371/journal.pone.0096106

Mononen, K., Konttinen, N., Viitasalo, J., \& Era, P. (2007). Relationships between postural balance, rifle stability and shooting accuracy among novice rifle shooters. Scandinavian Journal of Medicine \& Science in Sports, 17, 180-185. doi:10.1111/j.1600-0838. 2006.00549.x

Mononen, K., Viitasalo, J.T., Era, P., \& Konttinen, N. (2003). Optoelectronic measures in the analysis of running target shooting. Scandinavian Journal of Medicine \& Science in Sports, 13(3), 200-207. PubMed ID: 12753494 doi:10.1034/j.1600-0838.2003. 00130.x

Robles-Pérez, J.J., Aguirre-Puig, J.A., Montañez-González, P., Jesús Ramos-Campos, D., \& Clemente-Suárez, V.J. (2014). Technical analysis of close quarter combat with rifle. The Open Sports Sciences Journal, 7(1), 49-52. doi:10.2174/1875399x01407010049

Sattlecker, G., Buchecker, M., Gressenbauer, C., Müller, E., \& Lindinger, S.J. (2017). Factors discriminating high from low score performance in biathlon shooting. International Journal of Sports Physiology and Performance, 12(3), 377-384. PubMed ID: 27348149 doi:10.1123/ijspp.2016-0195

Zatsiorsky, V.M., \& Aktov, A.V. (1990). Biomechanics of highly precise movements: The aiming process in air rifle shooting. Journal of Biomechanics, 23(Suppl. 1), 35-41. doi:10.1016/0021-9290(90)90039-6 